\title{
Miocardiopatía chagásica: una causa de insuficiencia cardiaca de origen infeccioso
}

\author{
P. J. MARCHENA YGLESIAS, L. P. DE BENITO CORDÓN, D. GARCÍA MATEOS, \\ M. J. HERVÁS LAGUNA, M. RUIZ CLIMENTE
}

Servicio de Medicina Interna. Hospital Virgen de la Luz. Cuenca

\author{
CHAGASUC MIOCARDIOPHATY: AN INFECTIOUS AETIOLOGY OF \\ CONGESTIVE HEART FAILURE
}

\section{RESUMEN}

Se presenta el caso de un paciente latinoamericano con una miocardiopatía dilatada secundaria a una enfermedad de Chagas crónica tratada satisfactoriamente con medidas de soporte cardiológico. La intención es aportar una nueva etiología de insuficiencia cardiaca hasta ahora poco frecuente en nuestro medio pero que posiblemente vaya a aumentar debido a las corrientes migratorias actuales.

PALABRAS CLAVE: Enfermedad de Chagas. Miocardiopatía dilatada. Insuficiencia cardiaca.

\section{ABSTRACT}

We present a case report to Latin-American patient with dilated cardiomyopathy due to chronic Chagas' disease which treat with usually cardiologic support. We report a new aetiology of heart failure uncommon in our country but it would rise due to immigration from endemic countries.

KEY WORDS: Chagas' disease. Dilated cardiomyopathy. Congestive heart failure.

Marchena Yglesias PJ, De Benito Cordón LP, García Mateos D, Hervás Laguna MJ, Ruiz Climente M. Miocardiopatía chagásica: una causa de insuficiencia cardiaca de origen infeccioso. An Med Interna (Madrid) 2006; 23: 179-180.

\section{INTRODUCCIÓN}

En los últimos años estamos asistiendo a la aparición de enfermedades infecciosas previamente desconocidas en nuestro entorno debido a las corrientes migratorias de América Latina y África. Estos cuadros suelen ser causados por parásitos y virus con diferentes manifestaciones clínicas. Una de estas enfermedades es la de Chagas, tripanosomiasis americana con una alta prevalencia en Sudamérica y Centroamérica y que en su forma crónica se caracteriza por afectación miocárdica y digestiva.

A continuación presentamos el caso de un paciente con miocardiopatía dilatada chagásica que presentó buena evolución con tratamiento médico de soporte.

\section{CASO APORTADO}

Varón de 47 años de edad, natural de Bolivia y que por su trabajo de albañil había residido en Argentina y Brasil. Llevaba tres meses en España. Entre sus antecedentes destacaba una historia de esputos hemoptoicos por el que siguió tratamiento en su país durante un mes con un fármaco que no recordaba hacía 6 años. Asintomático desde entonces con una buena capacidad funcional ya que no había dejado de trabajar en todo este tiempo. Acudió a urgencias de nuestro centro por presentar desde hacía 5-7 días aumento progresivo de la disnea con ortopnea y disnea paroxística nocturna que le incapacitaba laboralmente. No refería fiebre ni ninguna otra sintomatología. En la exploración llamaba la aten- ción un soplo diastólico mitral, un tercer ruido y crepitantes bilaterales desde ambos ápex. La radiografía de tórax mostraba un patrón de edema intersticial bilateral en alas de mariposa compatible con insuficiencia cardiaca. El ecocardiograma reveló una miocardiopatía dilatada con una fracción de eyección del 10\%. El ECG mostró alteraciones inespecíficas de la repolarización y bigeminismos ocasionales sin llegar en ningún momento a taquicardias ventriculares. Ante la sospecha de origen infeccioso del proceso se solicitó reacción en cadena de la polimerasa (PCR) para Trypanosoma cruzi siendo positiva y serología Ig G, también positiva, que confirmó la cronicidad del mismo. Por otra parte el paciente refería dolor abdominal vago que junto con estreñimiento eran la manifestación de un megacolon que se confirmó radiológicamente. Con el diagnóstico de enfermedad de Chagas crónica con afectación miocárdica y colónica se inició tratamiento con diuréticos, IECAs, carvedilol y anticoagulación presentando el paciente muy buena evolución clínica y estando asintomático a las 24 horas del ingreso. El megacolon se solucionó con dieta con fibras y laxantes. En el momento actual el paciente está pendiente de ser valorado para transplante cardiaco.

\section{DISCUSIÓN}

La enfermedad de Chagas o tripanosomiasis americana es una entidad causada por un parásito denominado Trypanosoma cruzi y descrita inicialmente por Carlos Chagas en 1909. Dicha enfermedad es endémica en zonas rurales de Centroamérica y Sudamérica, con niveles socioeconómicos bajos. La Organización Mundial de la Salud estima que pueden existir

Trabajo aceptado: 3 de noviembre de 2005

Correspondencia: Pablo Javier Marchena Yglesias. C/ Berlín, 63-65, 2 3ª esc B. 08029 Barcelona. e-mail: pjmy1@yahoo.es 
entre 16-18 millones de infectados de los cuales 45.000 morirán al año por dicha enfermedad (1). Llama la atención la baja incidencia de esta enfermedad en los turistas del primer mundo cuando viajan a zonas endémicas a diferencia de los inmigrantes nativos hacia zonas urbanas de sus países o Europa y EE.UU. ya que traen consigo la enfermedad.

La fisiopatología se diferencia según sea la forma aguda o la crónica. La forma aguda se caracteriza por la penetración del parásito en las células miocárdicas lo que origina alteraciones mecánicas y eléctricas. También se observa destrucción del sistema nervioso autónomo que justifica las alteraciones digestivas posteriores (megaesófago y megacolon) (2). En la fase crónica la infamación aguda es sustituida por fibrosis miocárdica procediendo a un proceso de remodelación con el consiguiente deterioro de la función sistólica y diastólica y aneurismas apicales. La teoría de la autoinmunidad (anticuerpos del $T$. cruzi contra los cardiomiocitos) contribuiría a la patogenia en dicha fase crónica (1).

La clínica aguda se caracteriza por un proceso que se inicia alrededor de una semana tras inoculación del parásito presentando sintomatología general (fiebre, adenopatías, edema rostro y extremidades, hepatoesplenomegalia, etc.) y un chagoma (lesión indurada eritematosa). Cuando la infiltración es conjuntival es muy característico el signo de Romaña (edema palpebral y adenopatías). Sólo un $10 \%$ presenta miocarditis aguda y meningoencefalitis. La fase aguda se soluciona sin tratamiento en varias semanas o meses. Tras un periodo variable de tiempo (meses o años) en el que existe una parasitemia asintomática se presenta la fase crónica que puede tener manifestaciones cardiacas en formas de insuficiencia cardiaca -inicialmente derecha y posteriormente como miocardiopatía dilatada (como nuestro paciente)-, alteraciones eléctricas (tanto taquicardias, que pueden ser fatales, como bradiarritmias con diferentes tipos de bloqueos) y trombos murales con el riesgo de embolismos periféricos y pulmonares (1). Las manifestaciones digestivas son consecuencia de la destrucción de las neuronas del sistema nervioso simpático: el megaesófago (similar a la acalasia) y el megacolon (que se manifiesta con dolor abdominal vago y estreñimiento) (2). El diagnostico de la enfermedad se basa en el conjunto de la epidemiología, la clínica y las serologías (3). En la forma aguda la serología IgM contra T. cruzi es positiva. Otras técnicas pueden mostrar al parásito en un frotis sanguíneo en pacientes inmunocompetentes y en LCR, médula ósea o punción de ganglio en inmunodeprimidos. Los hemocultivos y los xenodiagnósticos requieren demasiado tiempo hasta obtener resultados y son de escasa sensibilidad. La forma crónica muestra una serología IgG positiva con la prudencia de los falsos positivos con leishmania, paludismo, sífilis y su poca especificidad, lo que requiere varias muestras antes de establecer un diagnóstico. La positividad a la PCR para el parásito en cualquier momento de la enfermedad es diagnóstico siempre que se apoye en una clínica y epidemiología compatible $(3,4)$.

El tratamiento está indicado en la infección aguda, en los inmunodeprimidos de cualquier etiología y en los accidentes profesionales con la manipulación de las muestras. Actualmente no existe un consenso sobre si el tratamiento en la fase crónica o la indeterminada tienen algún valor (5). Dicho tratamiento se basa en dos antiparasitarios: nifurtimox -que disminuye la duración, la gravedad y la mortalidad a expensas de muchos efectos secundarios (hematológicos, hepáticos, dermatológicos, neurológicos...) y con variabilidad regional de la efectividad (dosis 8-10 mg/kg/día/90-120 días)- y benznidazol (dosis $5 \mathrm{mgr} / \mathrm{kg} / \mathrm{día} / 60$ días) .Ninguno se ha mostrado superior al otro. En todo caso las medidas de sostén para la miocardiopatía (IECAs, diuréticos, anticoagulación) están indicados. Para el manejo de las alteraciones eléctricas, los antiarrítmicos del grupo I están contraindicados porque aumentan la mortalidad por Torsade de Pointes. Se recomienda manejo con amiodarona y limitado de betabloqueantes por su efecto depresor de la conducción y el inotropismo. Se han colocado desfibriladores y marcapasos en casos seleccionados. El trasplante cardiaco está indicado en clases funcionales III-IV de la NYHA con el riesgo de una reactivación de la enfermedad tras la inmunosupresión farmacológica, la cual suele ser más virulenta que la enfermedad nativa. Es por este motivo que está indicado el iniciar profilaxis con nifurtimox previa a la cirugía (1).

El pronóstico de la enfermedad chagásica es bueno en la fase aguda salvo que se presente como forma visceral. El problema lo encontramos en la fase crónica donde a los 10 años en pacientes asintomáticos la supervivencia es del $98 \%$, disminuyendo al $65 \%$ si tienen algún tipo de afectación electrocardiográfica y pasa al $9 \%$ en caso de presentar insuficiencia cardiaca. El 50\% de los pacientes con insuficiencia cardiaca fallece a los 2 años del diagnóstico (1). En el momento actual existen series muy cortas de pacientes transplantados donde las supervivencias oscilan entre el 46 y el $71 \%(6,7)$.

En resumen, se presenta uno de los primeros casos documentados en nuestro país de enfermedad de Chagas crónica con afectación cardiaca -junto con el publicado recientemente por Florián Sanz y cols. (3)- y digestiva. Es por ello que todo paciente con miocardiopatía dilatada que provenga de países endémicos, especialmente jóvenes en ausencia de factores de riesgo, habrá que valorar la posibilidad de una enfermedad de Chagas crónica.

\section{Bibliografía}

1. Acquatella H. Avances recientes en la miocardiopatía chagasica. Rev Esp Cardiol 1998; 51: 152-157.

2. Meneghelli UG. Chagasic enteropathy. Rev Soc Bras Med Trop 2004: 37 (3): 252-60.

3. Florián Sanz F, Gómez Navarro C, Castrillo García N, Pedrote Martínez A, Lage Gallé E. Miocardiopatía Chagásica en España: un diagnóstico a tener en cuenta. An Med Interna (Madrid) 2005; 22: 538540.

4. Kirchhoff LV. Especies de Tripanosoma (tripanosomiasis americana, enfermedad de Chagas): biología de los tripanosomas. En: Mandell, Dou-

glas y Bennett.Enfermedades infecciosas. Principios y Práctica. $4^{\mathrm{a}}$ edición Buenos Aires Ed. Panamericana; 1997. p. 2739-2748.

5. Acquatella H. Estado actual de la enferemdad de Chagas en Venezuela y de su manejo terapéutico. Gac. Med Caracas 2003; 111 (2) : 136-156.

6. Bocchi EA, Bellotti G, Mocelin AO, Bacal F ,Higuchi ML, Amato-Neto V, et al. Heart transplantation for chronic Chagas's heart disease. Ann Thorac Surg 1996; 61: 1727-1733.

7. Bocchi EA, Fiorelli A, et al. The paradoxal of survival results alter heart transplantation for cardiomyopathy caused by Trypanosoma Cruzi Ann Thorac Surg 2001;71:1833-1838. 